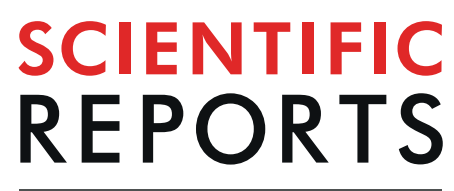

natureresearch

\title{
Low temperature synthesis via molten-salt method of r-BN nanoflakes, and their properties
}

\author{
Yang Chen, Xing Wang, ChaoYu, Jun Ding*, Chengji Deng \& Hongxi Zhu \\ $\mathrm{r}$-BN nanoflakes were synthesized using $\mathrm{KBH}_{4}$ and $\mathrm{NH}_{4} \mathrm{Cl}$ as the main raw material in a high-purity \\ nitrogen atmosphere. The effects of salt and salt-free conditions and heating temperature on the \\ synthesis of $B N$ were studied. The molten-salt method was used to synthesize $B N$ at $650^{\circ} \mathrm{C}$, which was \\ $250^{\circ} \mathrm{C}$ lower than the $\mathrm{BN}$ synthesis method without salt. Furthermore, at $1000^{\circ} \mathrm{C}$ the prepared flake- \\ like BN crystals showed good crystallinity, uniform morphology, a particle diameter of 200-300 nm, and \\ a thickness of $40-70 \mathrm{~nm}$. Moreover, the specific surface area of BN was $294.26 \mathrm{~m}^{2} / \mathrm{g}$. In addition, the BN \\ synthesized at $1100^{\circ} \mathrm{C}$ had a large elastic modulus value and good oxidation resistance.
}

Boron nitride (BN) is a new type of ceramic material with excellent performance and great potential for development. Due to its low dielectric constant ${ }^{1}$, wave transparency ${ }^{2,3}$, good electrical insulation ${ }^{4}$, low thermal expansion $^{5}$, high thermal conductivity ${ }^{6}$, high-temperature lubricity ${ }^{7}$, high-temperature stability ${ }^{8}$, and wide band gap ${ }^{9}$. Common $\mathrm{BN}$ contains hexagonal boron nitride (h-BN) with a graphite layered structure, cubic boron nitride $(\mathrm{c}-\mathrm{BN})$ with a diamond sphalerite structure, wurtzite boron nitride ( $\mathrm{w}-\mathrm{BN})$ with a hexagonal diamond wurtzite structure, rhombohedral boron nitride $(\mathrm{r}-\mathrm{BN})$ with a trigonal phase graphite structure, turbostratic boron nitride $(t-B N)$ with a laminar structure, and amorphous boron nitride ${ }^{10-15}$. Of these, $r-B N$ has high chemical stability and oxidation resistance, which makes it suitable for high-temperature resistant materials. Moreover, it also has a wide band gap, high thermal conductivity, and high resistivity, and can be used as an ideal substrate and heat sink material for high-power, high-temperature, and semiconductor materials.

At present, the research on $\mathrm{BN}$ is mainly focused on $\mathrm{h}-\mathrm{BN}^{16-20}$ and $\mathrm{c}-\mathrm{BN}^{21-23}$, and there has been little research on $\mathrm{r}$-BN. In recent years, researchers have mainly used chemical vapor deposition (CVD) to synthesize r-BN. Chubarov et al. performed an in-depth study of $\mathrm{r}$ - $\mathrm{BN}$. They used triethylboron and ammonia as precursors, and via CVD, $\mathrm{r}-\mathrm{BN}$ was produced on a sapphire substrate at $1500^{\circ} \mathrm{C}$ and a pressure of $7 \mathrm{kPa}$. The addition of a small amount of $\mathrm{SiH}_{4}$ to the gas mixture was also studied, and it was found that $\mathrm{Si}$ atoms acted as surface-active substances that stimulated the formation of high-quality $\mathrm{r}-\mathrm{BN}^{24}$. Subsequently, they formed an AlN buffer layer by in-situ nitridation, and $\mathrm{BN}$ was grown under low pressure using $\mathrm{H}_{2}$ as a carrier gas at $1200-1500^{\circ} \mathrm{C}^{25}$. After $\mathrm{SiC}$ was used as the substrate, it was found that growth temperature was $1500^{\circ} \mathrm{C}$, the $\mathrm{N} / \mathrm{B}$ ratio was 642 and the deposition pressure was $7 \mathrm{kPa}$ favored $\mathrm{r}$ - BN epitaxial growth, and no buffer layer was required ${ }^{26}$. In addition, Oku et al. ${ }^{27}$ prepared $\mathrm{r}$-BN particles of $50-1000 \mathrm{~nm}$ diameter via CVD on a graphite substrate from a $\mathrm{BCl}_{3}-\mathrm{NH}_{3}-\mathrm{H}_{2}$ reaction system at $1600^{\circ} \mathrm{C}$ and a total pressure of 3-5 Torr. Most of these methods require a high reaction temperature, a certain pressure, or a particular explosive atmosphere, and the purity of the synthesized r-BN is not high.

Other methods have also been used to prepare $\mathrm{r}-\mathrm{BN}$. Bao et al.$^{28}$ prepared highly crystalline $\mathrm{r}-\mathrm{BN}$ triangular nanosheets by using $\mathrm{NaNH}_{2}$ and $\mathrm{B}_{2} \mathrm{O}_{3}$ as raw materials in a solid-phase reaction in an autoclave at $600^{\circ} \mathrm{C}$ for $6 \mathrm{~h}$. The obtained r-BN triangular nanosheets had a width of approximately $300-500 \mathrm{~nm}$ and a thickness of approximately $50-90 \mathrm{~nm}$, but this method required a long reaction time and a certain pressure. Ye et al. ${ }^{13}$ prepared r-BN powders by using $\mathrm{Na}_{2} \mathrm{~B}_{4} \mathrm{O}_{7}$ and $\mathrm{Mg}$ as raw materials at $1000^{\circ} \mathrm{C}$ for $3 \mathrm{~h}$ under a nitrogen atmosphere with $\mathrm{NaCl}$ molten salt. The prepared $\mathrm{BN}$ was not high in purity and it contained h-BN, and the reaction temperature was high. Therefore, further research is still needed to improve the production process of $r$ - BN to obtain an r-BN preparation method that is simple and safe, uses a low synthesis temperature, and produces high yield.

In this work, we report on $\mathrm{r}-\mathrm{BN}$ synthesized in a $\mathrm{NaCl}-\mathrm{KCl}$ eutectic salt and a nitrogen atmosphere by using $\mathrm{KBH}_{4}$ and $\mathrm{NH}_{4} \mathrm{Cl}$ as the main raw materials, and compare the effect of the salt-free condition on the synthesis of r-BN. High-purity r-BN was synthesized at $650{ }^{\circ} \mathrm{C}$ and normal pressure by using the molten-salt synthesis (MSS $)^{29-34}$ method, which was $250^{\circ} \mathrm{C}$ lower than the temperature required when no salt was added, and it needed 

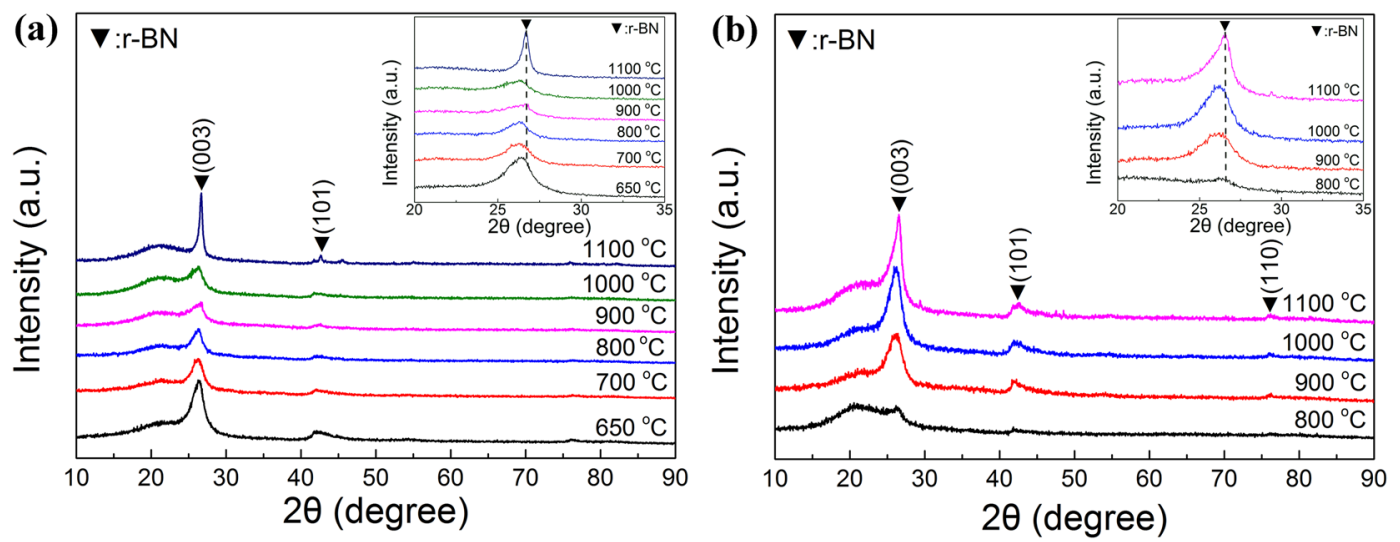

Figure 1. XRD patterns of samples heated at different temperatures for $4 \mathrm{~h}$ : (a) With salt; (b) Without salt.

a shorter reaction time. The effect of reaction temperature on the phase and microstructure of $r$-BN was studied. In addition, the chemical valence, optical properties, and specific surface area of the as-prepared r-BN nanoflakes were also investigated. One possible formation mechanism of $r-\mathrm{BN}$ is put forward. Finally, the prepared $r-\mathrm{BN}$ nanoflakes were subjected to antioxidant analysis.

\section{Methods}

Preparation of r-BN nanoflakes. Potassium borohydride $\left(\mathrm{KBH}_{4}, 97.0 \%\right.$ purity, Shanghai Aladdin Biochemical Technology Co., Ltd.) and ammonium chloride $\left(\mathrm{NH}_{4} \mathrm{Cl}, 99.5 \%\right.$ purity, Tianjin Kaitong Chemical Reagent Co., Ltd.) were used as the main raw materials; sodium chloride ( $\mathrm{NaCl}, 99.5 \%$ purity, Shanghai Aladdin Biochemical Technology Co., Ltd.) and potassium chloride (KCl, 99.5\% purity, Shanghai Aladdin Biochemical Technology Co., Ltd.) were used as the molten salt to synthesize $\mathrm{r}-\mathrm{BN}$ in high-purity nitrogen (99.999\%). The raw materials $\left(\mathrm{KBH}_{4} / \mathrm{NH}_{4} \mathrm{Cl}\right.$, molar ratio of $\left.1: 2\right)$ and molten salt (molar ratio of $\mathrm{NaCl} / \mathrm{KCl}=1: 1$ ) were mixed at a mass ratio of 6:5. The mixture was heated from $25^{\circ} \mathrm{C}$ at a ramp of $2{ }^{\circ} \mathrm{C} / \mathrm{min}$ to $300^{\circ} \mathrm{C}$ in a vertical corundum tube furnace, and then heated to $650-1100^{\circ} \mathrm{C}$ at a rate of $4^{\circ} \mathrm{C} / \mathrm{min}$ and held for $4 \mathrm{~h}$. After that, the reaction products were cooled in the furnace to room temperature. The reaction products were soaked in distilled water for $2 \mathrm{~h}$ and washed with distilled water two to three times by using an ultrasonic cleaner to remove unreacted materials and molten salts. The final product was then dried at $110^{\circ} \mathrm{C}$ to obtain $\mathrm{r}-\mathrm{BN}$ nanoflakes.

Because $\mathrm{NH}_{4} \mathrm{Cl}$ would become volatile above $330^{\circ} \mathrm{C}$, the mixture was heated from $25^{\circ} \mathrm{C}$ to $300^{\circ} \mathrm{C}$ at a rate of $2^{\circ} \mathrm{C} / \mathrm{min}$ so that $\mathrm{KBH}_{4}$ and $\mathrm{NH}_{4} \mathrm{Cl}$ could produce more stable substances to reduce the loss in the subsequent $\mathrm{NH}_{4} \mathrm{Cl}$ heating process, and the amount of $\mathrm{NH}_{4} \mathrm{Cl}$ was greater than that of $\mathrm{KBH}_{4}$ to compensate for the loss of $\mathrm{NH}_{4} \mathrm{Cl}$ at high temperature.

The reaction for synthesizing BN can be described as follows:

$$
\begin{gathered}
\mathrm{KBH}_{4(\mathrm{~s})}+\mathrm{NH}_{4} \mathrm{Cl}_{(\mathrm{s})} \rightarrow \mathrm{BN}_{(\mathrm{s})}+\mathrm{KCl}_{(\mathrm{s})}+4 \mathrm{H}_{2(\mathrm{~g})} \\
\Delta \mathrm{G}^{\theta}=-265.01-0.41 \mathrm{~T}\left(\mathrm{KJ} \cdot \mathrm{mol}^{-1}\right)
\end{gathered}
$$

Characterization. The phases of the products were analyzed by X-ray diffraction (XRD, PANalytical, X'Pert Pro) using $\mathrm{CuK} \alpha$ radiation. The element species and chemical valences of the samples' surfaces were studied by X-ray photoelectron spectroscopy (XPS, Thermo Fisher Scientific, ESCALAB 250Xi) with AlKo radiation. The morphology and crystal structure were observed by scanning electron microscopy (SEM, FEI, Nova 400 Nano SEM), high-resolution transmission electron microscopy (HRTEM, JEOL, JEM-2100 UHR STEM/EDS) and atomic force microscopy (AFM, NT-MDT Prima). In addition, a synchronous thermal analyzer with thermogravimetric analysis-differential thermal analysis (TG-DTA, NETZSCH, STA449F3) was used to investigate the oxidation resistance of the as-prepared $\mathrm{BN}$, and the generation process of the $\mathrm{BN}$. The infrared absorption of the product was tested using the Fourier transform infrared (FTIR, Thermo Fisher Scientific, Nicolet iS 50) spectrum. The Brunauer-Emmett-Teller (BET) specific surface area of the as-prepared BN was characterized using a fully automatic surface area and porosity analyzer (JWGB, JW-BK100C).

\section{Results and Discussion}

Phase analysis. Figure la shows the XRD patterns of samples heated at different temperatures for $4 \mathrm{~h}$ in $\mathrm{NaCl}-\mathrm{KCl}$ eutectic salts. At $650^{\circ} \mathrm{C}$, the diffraction peak of $\mathrm{BN}$ appeared at $25-30^{\circ}$, but the amount of $\mathrm{BN}$ obtained after water washing of the fired product was small. This is because the molten salt partially melted (the eutectic melting temperature of $\mathrm{NaCl}-\mathrm{KCl}$ is $657^{\circ} \mathrm{C}$ ), and generated a small amount of liquid phase environment. The raw materials of $\mathrm{KBH}_{4}$ and $\mathrm{NH}_{4} \mathrm{Cl}$ were mostly evaporated or decomposed after a long time at low temperature. This indicates that an excessive holding time at low temperatures was not conducive to the synthesis of BN. As the heating temperature rose to $1100^{\circ} \mathrm{C}$, the main diffraction peak of $\mathrm{BN}$ became sharp, and the peak intensity was maximized. This shows that $\mathrm{BN}$ synthesized at $1100^{\circ} \mathrm{C}$ had the best crystallinity. Furthermore, there are two 


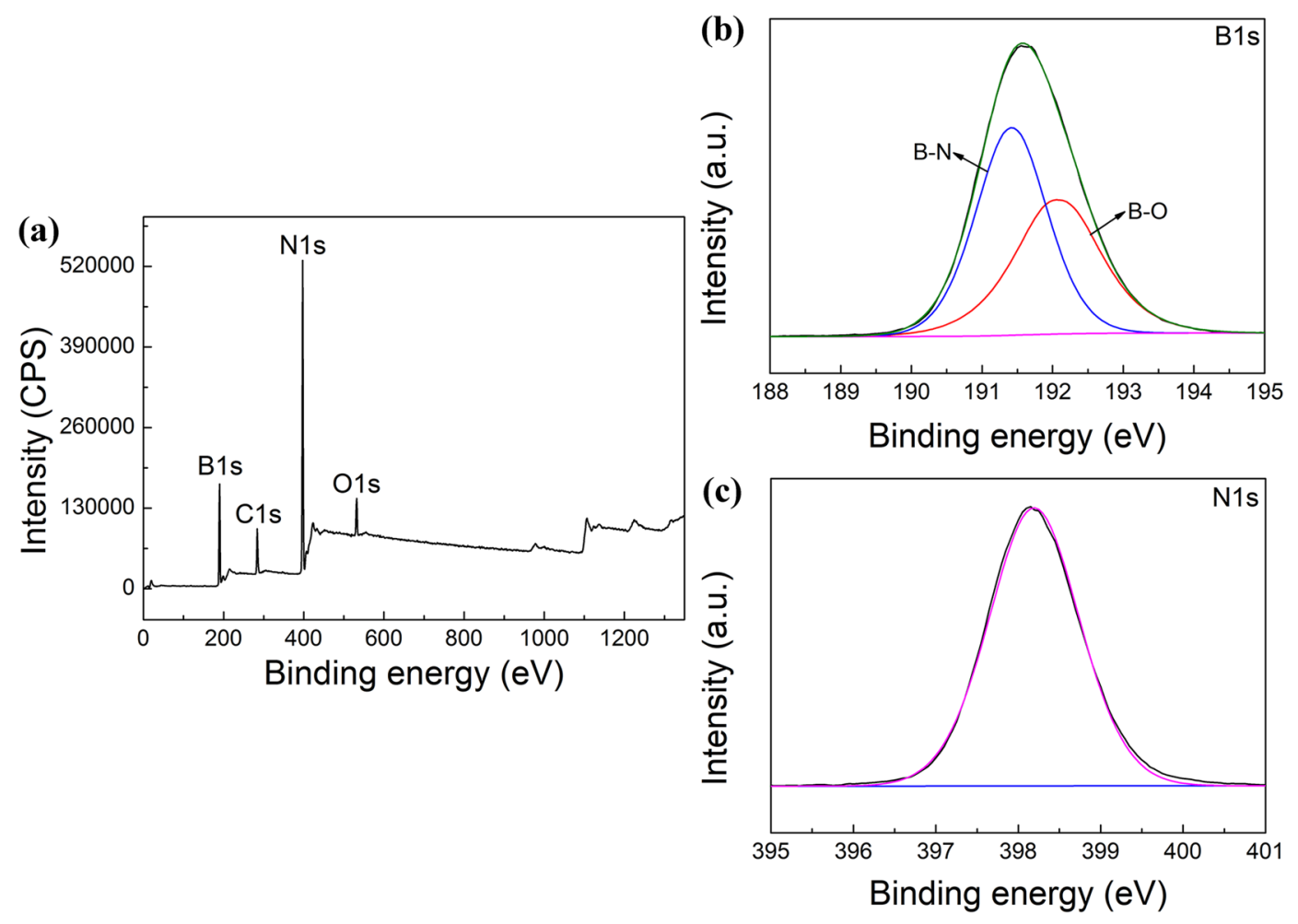

Figure 2. XPS spectra of $\mathrm{BN}$ synthesized at $1100^{\circ} \mathrm{C}$ in $\mathrm{NaCl}-\mathrm{KCl}$ eutectic salt: (a) The full spectrum of the product XPS; (b) B1s spectra of $\mathrm{BN}$; (c) N1s spectra of $\mathrm{BN}$.

\begin{tabular}{|l|l|l|l|l|}
\hline Peak & Peak BE $(\mathrm{eV})$ & FWHM $(\mathrm{eV})$ & Area & Atomic $(\%)$ \\
\hline O1s & 532.77 & 3.23 & $1.917 \times 10^{5}$ & 3.46 \\
\hline C1s & 284.94 & 3.04 & $2.098 \times 10^{5}$ & 9.64 \\
\hline N1s & 398.09 & 2.82 & $1.351 \times 10^{6}$ & 39.08 \\
\hline B1s & 190.75 & 2.71 & $4.082 \times 10^{5}$ & 47.82 \\
\hline
\end{tabular}

Table 1. The relative content of elements in the XPS spectra of Fig. 2.

diffraction peaks: the peaks at diffraction angles $(2 \theta)$ of $26.717^{\circ}$ and $42.620^{\circ}$ can be indexed to r-BN $((003)$ and (101)), respectively. In addition, a small amount of $\mathrm{O}_{2}$ from the $\mathrm{N}_{2}$ gas caused slight oxidation of the $\mathrm{BN}$ during the synthesis. A weaker hump is found at a diffraction angle of $22^{\circ}$, which corresponds to amorphous $\mathrm{B}_{2} \mathrm{O}_{3}$.

Figure $1 \mathrm{~b}$ shows the XRD patterns of samples heated at different temperatures for $4 \mathrm{~h}$ without adding salt. No $\mathrm{BN}$ was generated at $800^{\circ} \mathrm{C}$. When the heating temperature was $900^{\circ} \mathrm{C}, \mathrm{BN}$ started to form. At $900-1100^{\circ} \mathrm{C}$, as the heating temperature increased, the peak intensity of $\mathrm{BN}$ increased and its peak became sharper. However, as the heating temperature rose to $1100^{\circ} \mathrm{C}$, the diffraction peak of the (003) crystal plane showed a slight shift in the higher angle direction, accompanied by a narrowing of the diffraction peak. Figure la also shows this phenomenon. According to the Bragg equation ( $2 \mathrm{~d} \sin \theta=\mathrm{n} \lambda)$, the diffraction peak is shifted to a larger angle, the lattice spacing of $\mathrm{BN}$ is decreased, and the lattice is shrunken along the c-axis orientation. The grain size is larger in the direction perpendicular to the $(00 l)$ direction, resulting in a narrowing of the $(003)$ peak by continuous X-ray scattering ${ }^{35}$. In addition, a small diffraction peak appears at an angle of $75.955^{\circ}$, which is the (110) crystal plane of $\mathrm{r}-\mathrm{BN}$.

XPS can be used to check all elemental information in a substance. Figure 2a shows the full spectrum of the product XPS. In Fig. 1a, the O1s peak $(532.77 \mathrm{eV})$ is attributed to amorphous $\mathrm{B}_{2} \mathrm{O}_{3}$. The $\mathrm{C} 1 \mathrm{~s}$ peak $(284.94 \mathrm{eV})$ is attributed to the addition of $\mathrm{C}$ as an internal standard substance. The binding energies of $\mathrm{B} 1 \mathrm{~s}$ and $\mathrm{N} 1 \mathrm{~s}$ are $190.75 \mathrm{eV}$ and $398.09 \mathrm{eV}$, respectively. As shown in Fig. 2b, the B1s spectrum has two peaks at $191.42 \mathrm{eV}$ and $192.04 \mathrm{eV}$, corresponding to B-N and B-O, respectively. Moreover, the N1s spectrum has a peak at $398.19 \mathrm{eV}$,

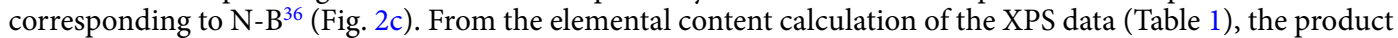
consists of $91.87 \% \mathrm{BN}$ and $8.13 \% \mathrm{~B}_{2} \mathrm{O}_{3}$.

Microstructure analysis. Figure 3 shows SEM images of the BN synthesized at different temperatures in $\mathrm{NaCl}-\mathrm{KCl}$ eutectic salts. Figure $3 \mathrm{a}$ shows many thin and poorly crystallized $\mathrm{BN}$ nanoflakes at $800^{\circ} \mathrm{C}$, which are stacked in a staggered relation to each other to form many small holes. The production of these holes may have been caused by the volatilization of the raw materials or the gases produced by the reaction. When the heating 

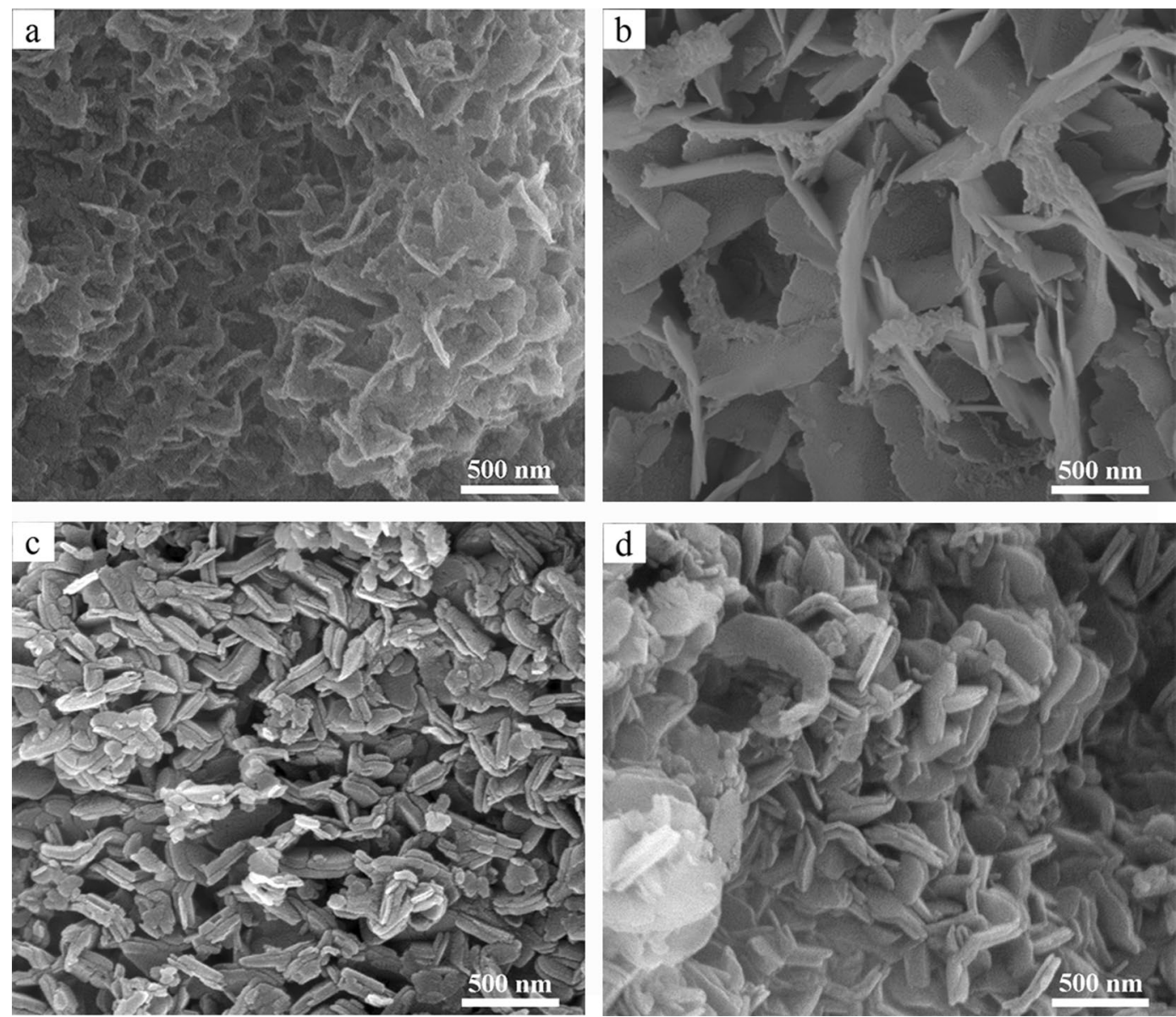

Figure 3. SEM images of $\mathrm{BN}$ synthesized at different temperatures in $\mathrm{NaCl}-\mathrm{KCl}$ eutectic salts: (a) $800^{\circ} \mathrm{C}$; (b) $900^{\circ} \mathrm{C}$; (c) $1000^{\circ} \mathrm{C}$; (d) $1100^{\circ} \mathrm{C}$.

temperature rose to $900^{\circ} \mathrm{C}, \mathrm{BN}$ nanoflakes grew (Fig. 3b). At $1000^{\circ} \mathrm{C}$, the as-synthesized $\mathrm{BN}$ has a uniform morphology with a diameter of 200-300 $\mathrm{nm}$ and a thickness of $40-70 \mathrm{~nm}$, and the two grains grow close together (Fig. $3 \mathrm{c}$ ). As the heating temperature was increased to $1100^{\circ} \mathrm{C}$, the morphology of the BN was approximately unchanged, but some BN nanoflakes became curled (Fig. 3d). This may have occurred to reduce the surface free energy, so that the $\mathrm{BN}$ nanoflakes were in the lowest energy state to eliminate the internal stress of the flake structure. The nanoflake diameter is approximately $300-500 \mathrm{~nm}$ and the thickness is approximately $25-50 \mathrm{~nm}$.

Figure 4 shows SEM images of the $\mathrm{BN}$ synthesized at different temperatures without adding salt. Figure $4 \mathrm{a}$ shows that irregular grains were generated at $800^{\circ} \mathrm{C}$, and the low temperature was not conducive to the growth of grains. Some irregular BN nanoflakes appear at $900^{\circ} \mathrm{C}$ (Fig. $4 \mathrm{~b}$ ). When the temperature is $1000^{\circ} \mathrm{C}$, the $\mathrm{BN}$ nanoflakes are not uniform in size, and many small flake-like particles of $\mathrm{BN}$ are formed on the large flake-like $\mathrm{BN}$, and the small flake-like BN has grown tightly together (Fig. 4c). As the temperature rose to $1100^{\circ} \mathrm{C}$, the flake-like BN grew to a diameter of approximately $400-700 \mathrm{~nm}$, and a thickness of approximately $50-75 \mathrm{~nm}$ (Fig. $4 \mathrm{~d}$ ).

The effects of different temperatures on the morphology and crystal structure of BN formed in a molten-salt environment were further investigated by TEM (Fig. 5). Figure $5 \mathrm{a}$ shows that the $\mathrm{BN}$ is very thin, and has grown with a staggered profile, with an average thickness of approximately $10 \mathrm{~nm}$ at $700^{\circ} \mathrm{C}$. At $800^{\circ} \mathrm{C}$, the crystallinity of the $\mathrm{BN}$ is not good, and the $\mathrm{BN}$ nanoflakes have rough boundaries and disordered edges (Fig. $5 \mathrm{~b}$ ). At $900^{\circ} \mathrm{C}$, the tip of the generated $\mathrm{BN}$ is clearly bifurcated, which could be described as two grains of BN grown into one grain along the $\mathrm{c}$-axis direction (Fig. $5 \mathrm{c}$ ). At $1000^{\circ} \mathrm{C}$, the $\mathrm{BN}$ nanoflakes have grown closely together and are of uniform size (Fig. 5d), which is consistent with Fig. 3c, and this further shows that the morphology of the BN synthesized at $1000^{\circ} \mathrm{C}$ is better.

In addition, Fig. 6 shows the TEM, HRTEM, and selected area electron diffraction (SAED) images of BN synthesized at $1100^{\circ} \mathrm{C}$ in $\mathrm{NaCl}-\mathrm{KCl}$ eutectic salts. Figure 6a shows a typical TEM image of BN nanoflakes, which have a diameter of $70-130 \mathrm{~nm}$ and a thickness of 5-30 nm, and some BN nanoflakes are wrinkled. The inset in Fig. 6a shows the SAED pattern of $\mathrm{r}$-BN with some diffraction spots distributed over the diffraction rings, indicating that the $\mathrm{BN}$ nanoflakes have a polycrystalline structure. The diffraction rings are indexed as the (003) and (101) planes of $\mathrm{r}-\mathrm{BN}$, which corresponds to the XRD results. Figure $6 \mathrm{~b}$ is the HRTEM image of the BN in Fig. 6a. The lattice spacing of the $\mathrm{BN}$ in the smooth area is $0.34 \mathrm{~nm}$, which corresponds to the (003) plane of r-BN (3.334 $\AA$, ICDD No. 00-045-1171) $)^{13}$, indicating that the BN nanoflakes grew in a direction perpendicular to the (003) crystal plane. This directly confirms our interpretation of the phenomenon shown in Fig. 1. However, the lattice spacing 

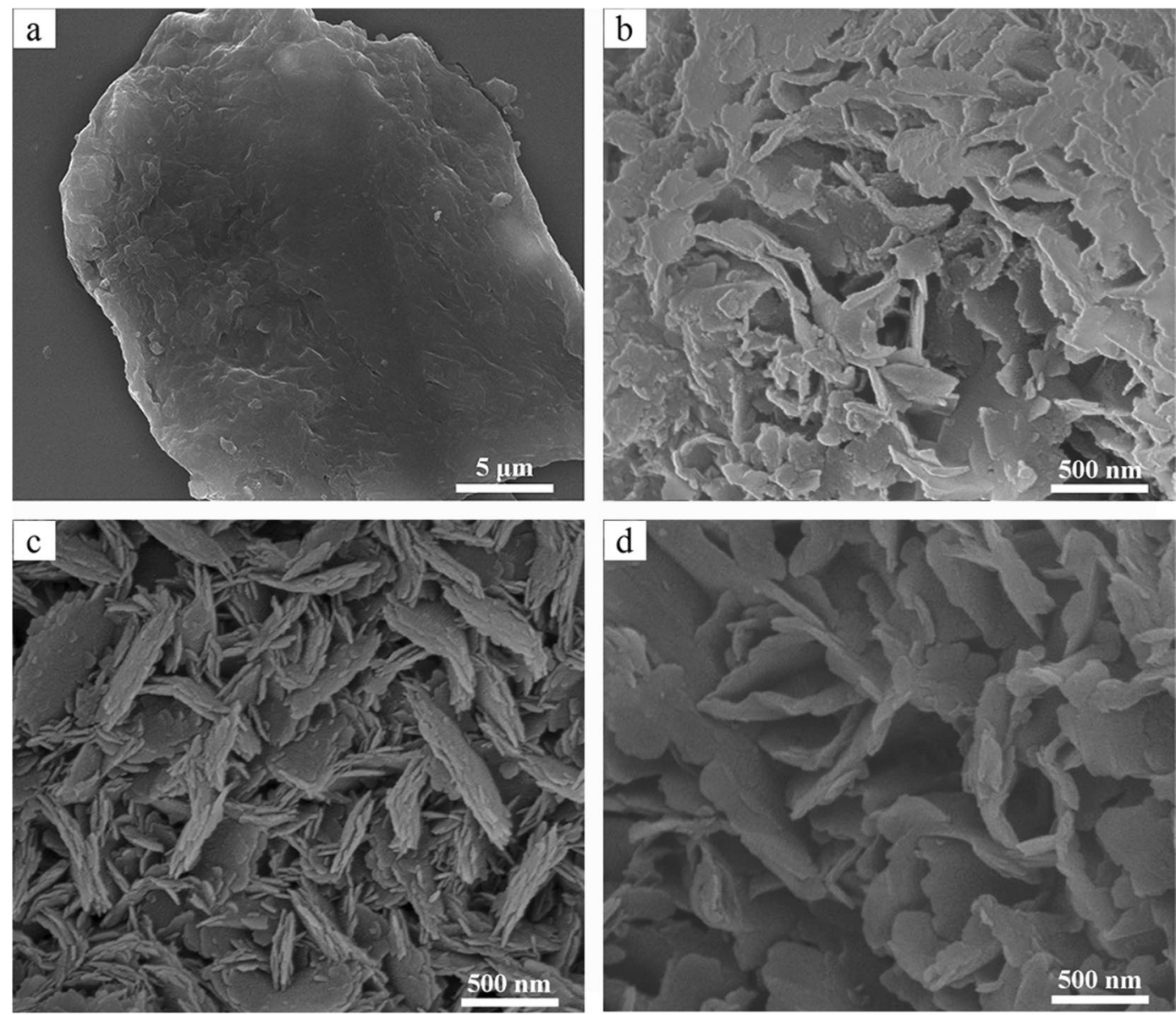

Figure 4. SEM images of $\mathrm{BN}$ synthesized at different temperatures without adding salt: (a) $800^{\circ} \mathrm{C}$; (b) $900^{\circ} \mathrm{C}$; (c) $1000^{\circ} \mathrm{C} ;$ (d) $1100^{\circ} \mathrm{C}$.

at the fold is $0.35 \mathrm{~nm}$. This may be due to the rotation of the lattice plane, which caused the BN nanoflakes to curl and exhibit folds on the crystal plane ${ }^{20}$, as in Fig. $3 \mathrm{~d}$.

The morphology of $\mathrm{BN}$ synthesized at $1100^{\circ} \mathrm{C}$ in $\mathrm{NaCl}-\mathrm{KCl}$ eutectic salts was further analyzed by AFM. The three-dimensional view and enlarged plan view of BN are shown in Fig. 7a,b. It can be clearly observed that BN has a flake-like structure, which is consistent with the previous SEM and TEM images (Figs 3d and 6a). The flakes are formed in a continuous step shape, the steps do not overlap each other, the surface is flat and smooth, and the width of the $\mathrm{BN}$ is approximately $400-450 \mathrm{~nm}$. The elastic modulus of the $\mathrm{BN}$ is approximately $1.60 \mathrm{GPa}$ (Fig. $7 \mathrm{c}$ ).

FTIR spectrum of r-BN. The FTIR spectrum of the $\mathrm{BN}$ synthesized at $650^{\circ} \mathrm{C}$ and $1100^{\circ} \mathrm{C}$ in $\mathrm{NaCl}-\mathrm{KCl}$ eutectic salt is shown in Fig. 8 . The BN synthesized at $650^{\circ} \mathrm{C}$ shows two strong absorption peaks at $1377 \mathrm{~cm}^{-1}$ and $790 \mathrm{~cm}^{-1}$, which can be referred to as the in-plane B-N stretching vibration and the out-of-plane B-N-B bending vibration, respectively ${ }^{25}$. However, the $\mathrm{BN}$ synthesized at $1100^{\circ} \mathrm{C}$ forms a weaker and broader absorption peak at $3428 \mathrm{~cm}^{-1}$, which may be due to the $\mathrm{O}-\mathrm{H}$ bond of water adsorbed on the sample surface. The infrared analysis results are consistent with the XRD results, and this further confirms that the resulting product is high-purity r-BN.

Specific surface area analysis of r-BN. It is well known that the higher the specific surface area of a catalyst carrier, the more favorable the dispersion of the active components, and thus the more conducive to the improvement of its catalytic activity. Therefore, the high specific surface area of BN is of great value as a catalyst carrier ${ }^{37,38}$. With its high specific surface area, BN can be used not only as a catalyst carrier but also as an adsorbent and hydrogen storage material ${ }^{39-41}$. Figure 9 shows the specific surface area of BN synthesized at different temperatures, with and without salt. The synthesis temperature was $900-1100^{\circ} \mathrm{C}$, and the specific surface area of the BN synthesized by $\mathrm{MSS}^{42-49}$ method is $142.61-294.26 \mathrm{~m}^{2} / \mathrm{g}$. The specific surface area of the BN synthesized at $1000^{\circ} \mathrm{C}$ is the largest, at $294.26 \mathrm{~m}^{2} / \mathrm{g}$. This shows that the $\mathrm{BN}$ particles produced at this temperature were smaller, as is further confirmed by Fig. $3 \mathrm{~b}-\mathrm{d}$.

When no salt was added, as the synthesis temperature increased, and the specific surface area of BN, which was in the range of $151.51-251.85 \mathrm{~m}^{2} / \mathrm{g}$, decreased, indicating that as the temperature rose, the product particles 

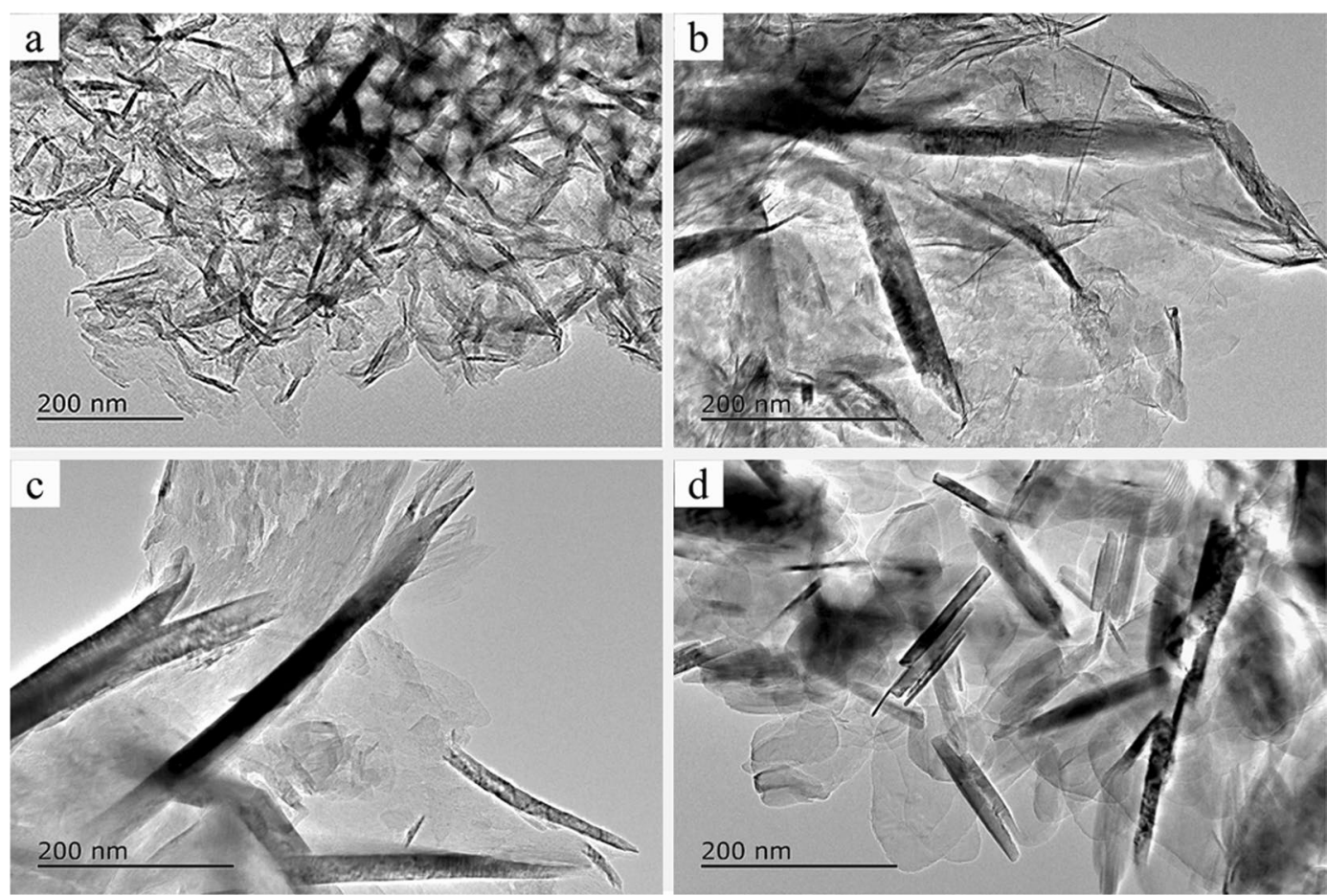

Figure 5. TEM images of $\mathrm{BN}$ synthesized at different temperatures in $\mathrm{NaCl}-\mathrm{KCl}$ eutectic salts: (a) $700^{\circ} \mathrm{C}$; (b) $800^{\circ} \mathrm{C}$; (c) $900^{\circ} \mathrm{C}$; (d) $1000^{\circ} \mathrm{C}$.
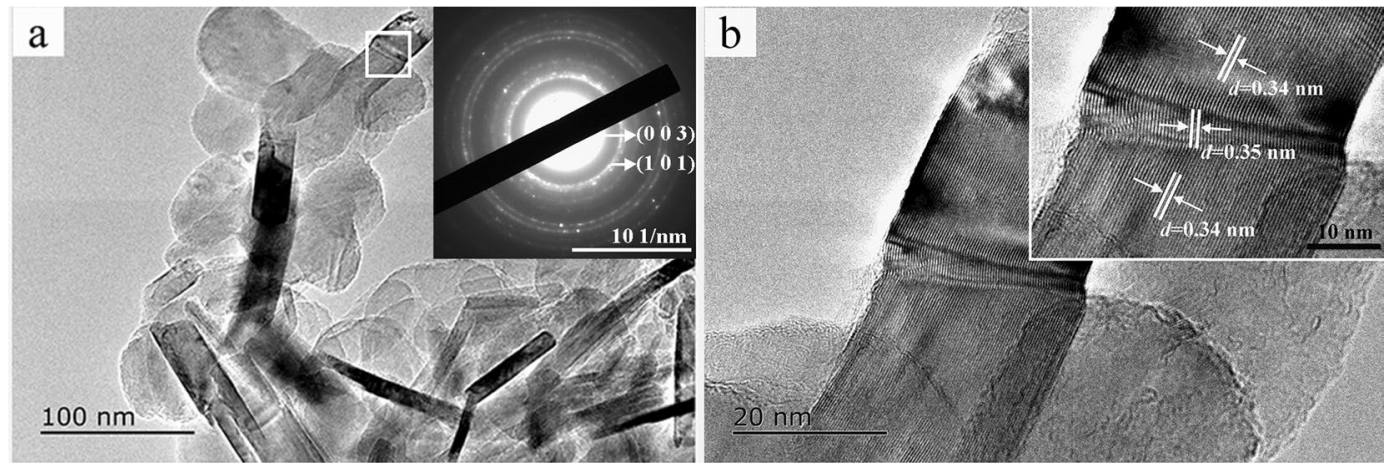

Figure 6. TEM and SAED (a), HRTEM (b) images of $\mathrm{BN}$ synthesized at $1100^{\circ} \mathrm{C}$ in $\mathrm{NaCl}-\mathrm{KCl}$ eutectic salts.

grew. This is further confirmed by Fig. $4 \mathrm{~b}-\mathrm{d}$. In addition, the two synthesis methods of BN were compared, and the specific surface area of the BN synthesized by the MSS method at $1000^{\circ} \mathrm{C}$ was found to be the largest.

Reaction mechanism of r-BN. Figure 10 shows the TG-DTA curves of the raw materials heated from $25^{\circ} \mathrm{C}$ at $5^{\circ} \mathrm{C} / \mathrm{min}$ to $1100^{\circ} \mathrm{C}$ under a nitrogen atmosphere. The TG-DTA curves of the raw materials heated to $1100^{\circ} \mathrm{C}$ in $\mathrm{NaCl}-\mathrm{KCl}$ eutectic salts are shown in Fig. 10a. As the heating temperature increased, an endothermic peak appeared at $259^{\circ} \mathrm{C}$ with the partial volatilization or decomposition of $\mathrm{NH}_{4} \mathrm{Cl}$ (Eq. 2). With the increase in heating temperature, there was a faint endothermic peak at $582^{\circ} \mathrm{C}$ due to the decomposition of $\mathrm{KBH}_{4}$ (Eq. 3). During this process, the generated $\mathrm{KH}$ and $\mathrm{HCl}$ reacted to generate $\mathrm{H}_{2}$ (Eq. 4). An exothermic peak appeared at $775^{\circ} \mathrm{C}$, and the mass of the sample decreased with increasing temperature. The reason for this is that the resulting intermediate $\mathrm{B}_{3} \mathrm{~N}_{3} \mathrm{H}_{6}$ (Eq. 5) was slowly dehydrogenated and became exothermic, resulting in the formation of $\mathrm{BN}$ (Eq. 6) ${ }^{50,51}$. The total weight loss was approximately $66 \%$.

$$
\begin{gathered}
\mathrm{NH}_{4} \mathrm{Cl}_{(\mathrm{s})} \rightarrow \mathrm{NH}_{3(\mathrm{~g})}+\mathrm{HCl}_{(\mathrm{g})} \\
\Delta \mathrm{G}^{\theta}=97.72-0.27 \mathrm{~T}\left(\mathrm{KJ} \cdot \mathrm{mol}^{-1}\right)
\end{gathered}
$$


a

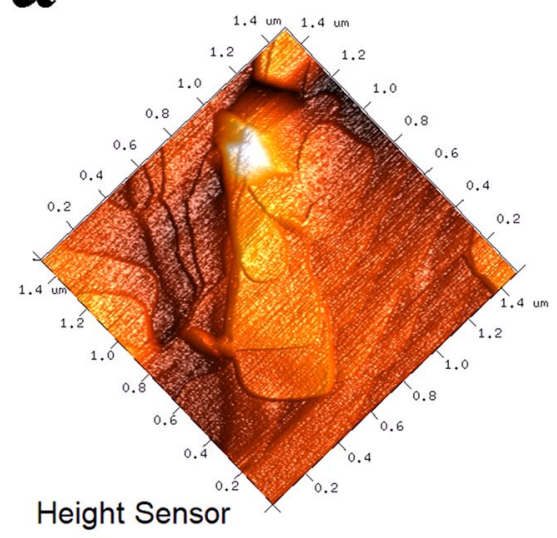

b

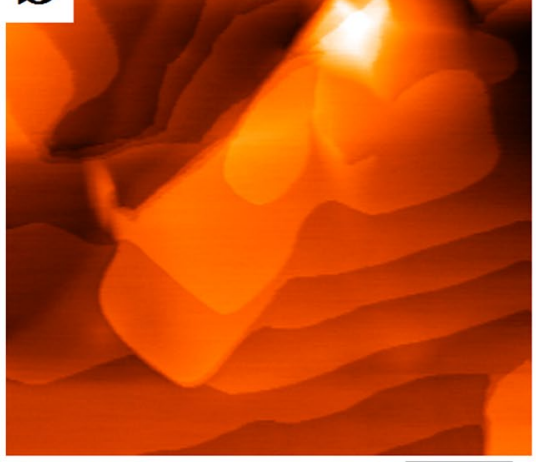

$33.6 \mathrm{~nm}$
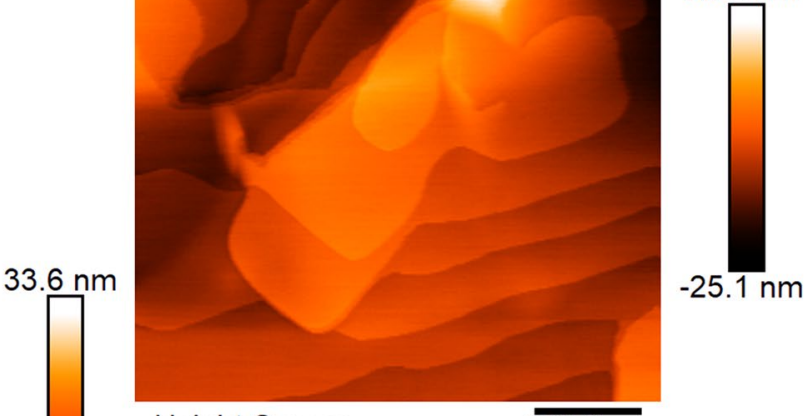

Height Sensor

$3 \overline{00.0 \mathrm{~nm}}$
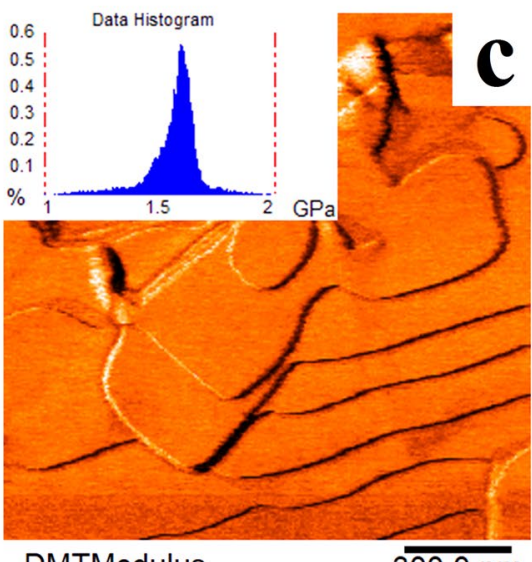

DMTModulus

$3 \overline{00.0 \mathrm{~nm}}$

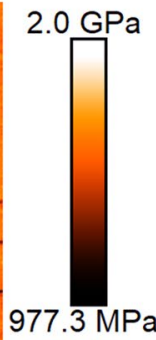

Figure 7. AFM images of $\mathrm{BN}$ synthesized at $1100^{\circ} \mathrm{C}$ in $\mathrm{NaCl}-\mathrm{KCl}$ eutectic salts: (a) Three-dimensional view; $(\mathbf{b}, \mathbf{c})$ Enlarged plan view.

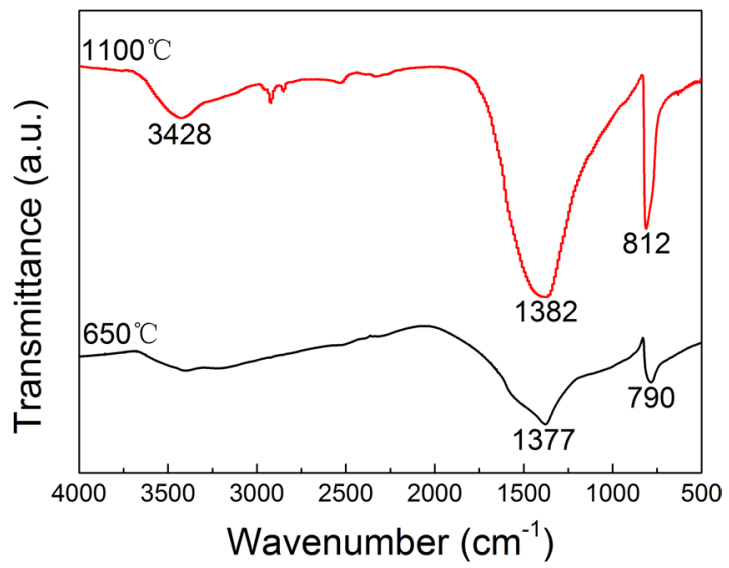

Figure 8. FTIR spectrum of the $\mathrm{BN}$ synthesized at $650^{\circ} \mathrm{C}$ and $1100^{\circ} \mathrm{C}$ in $\mathrm{NaCl}-\mathrm{KCl}$ eutectic salt.

$$
\begin{gathered}
\mathrm{KBH}_{4(\mathrm{~s})} \rightarrow \mathrm{BH}_{3(\mathrm{~g})}+\mathrm{KH}_{(\mathrm{g})} \\
\Delta \mathrm{G}^{\theta}=377.28-0.26 \mathrm{~T}\left(\mathrm{KJ} \cdot \mathrm{mol}^{-1}\right) \\
\mathrm{KH}_{(\mathrm{g})}+\mathrm{HCl}_{(\mathrm{g})} \rightarrow \mathrm{KCl}_{(\mathrm{s})}+\mathrm{H}_{2(\mathrm{~g})} \\
\Delta \mathrm{G}^{\theta}=-413.23+0.15 \mathrm{~T}\left(\mathrm{KJ} \cdot \mathrm{mol}^{-1}\right)
\end{gathered}
$$




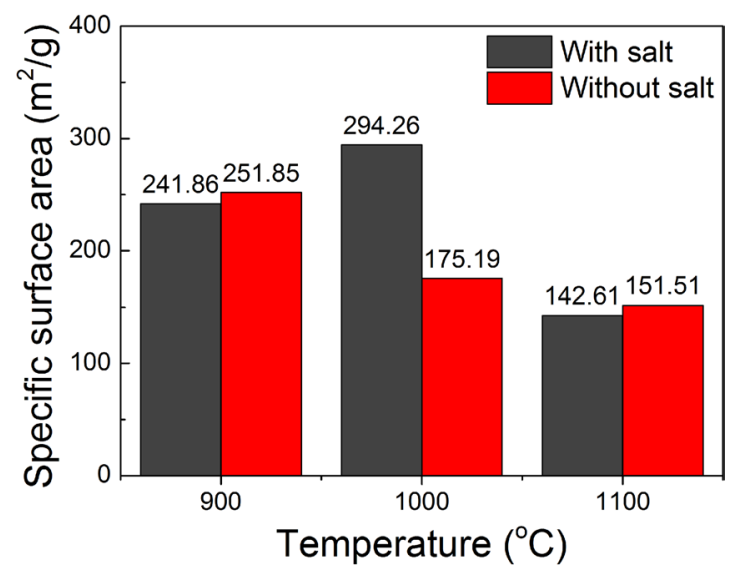

Figure 9. Specific surface area of BN synthesized at different temperatures, with and without salt.
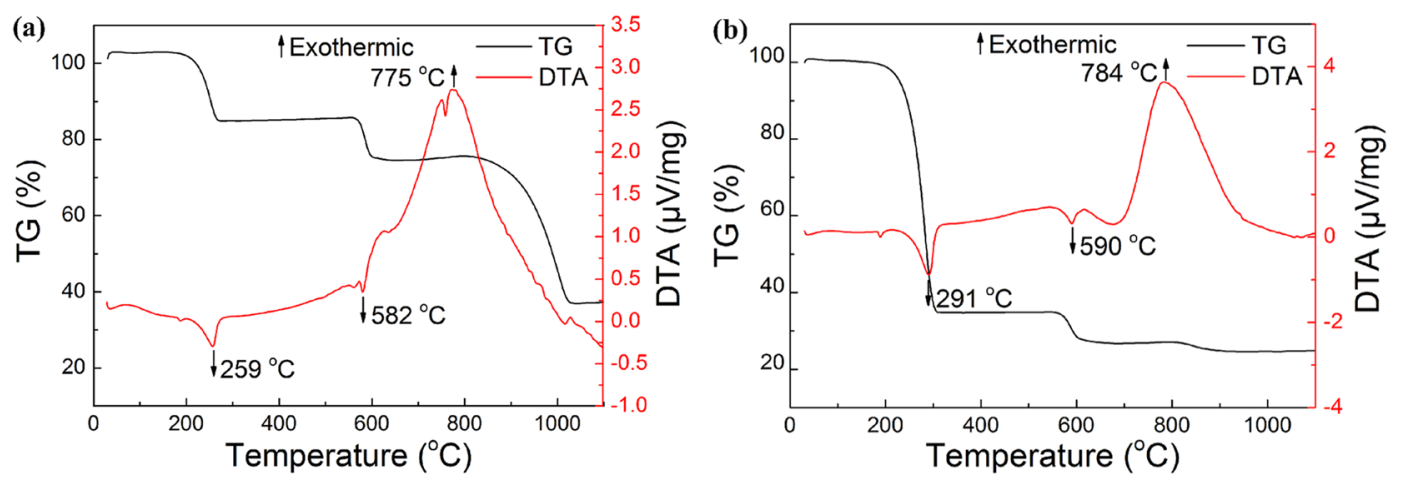

Figure 10. TG-DTA curves of raw materials heated to $1100^{\circ} \mathrm{C}$ under nitrogen: (a) With salt; (b) Without salt.

$$
\begin{gathered}
3 \mathrm{NH}_{3(\mathrm{~g})}+3 \mathrm{BH}_{3(\mathrm{~g})} \rightarrow \mathrm{B}_{3} \mathrm{~N}_{3} \mathrm{H}_{6(\mathrm{~g})}+6 \mathrm{H}_{2(\mathrm{~g})} \\
\Delta \mathrm{G}^{\theta}=-642.95-0.02 \mathrm{~T}\left(\mathrm{KJ} \cdot \mathrm{mol}^{-1}\right) \\
\mathrm{B}_{3} \mathrm{~N}_{3} \mathrm{H}_{6(\mathrm{~g})} \rightarrow 3 \mathrm{BN}_{(\mathrm{s})}+3 \mathrm{H}_{2(\mathrm{~g})} \\
\Delta \mathrm{G}^{\theta}=-275.26-0.18 \mathrm{~T}\left(\mathrm{KJ} \cdot \mathrm{mol}^{-1}\right)
\end{gathered}
$$

Figure 10b shows the TG-DTA curves of the raw materials heated to $1100^{\circ} \mathrm{C}$ without adding salt. The quality change in the sample presents in two distinct phases. In the first stage, the temperature range is approximately $200-300^{\circ} \mathrm{C}$ and the corresponding mass loss is $64 \%$. In the second stage, the temperature range is $500-700^{\circ} \mathrm{C}$, corresponding to an $8 \%$ mass loss. In addition, there is a slight weight loss at $800-900^{\circ} \mathrm{C}$, corresponding to a $2 \%$ mass loss. The total weight loss is $74 \%$. Compared with Fig. 10a, the weight loss is quite large, which means that the synthesis of BN using the MSS method can effectively reduce the loss of raw materials during the reaction process.

The reaction mechanism for forming BN was analyzed in conjunction with Fig. 10. A possible formation process for $\mathrm{r}-\mathrm{BN}$ is shown in Fig. 11 . At approximately $200-300^{\circ} \mathrm{C}, \mathrm{NH}_{4} \mathrm{Cl}$ is partially volatilized or decomposed into $\mathrm{NH}_{3}$. When the temperature is heated to $350^{\circ} \mathrm{C}$, the $\mathrm{KBH}_{4}$ begins to melt. Because $\mathrm{KBH}_{4}$ is easily decomposed by inorganic acid (e.g., $\mathrm{HCl}$ ), under the pressure generated by the $\mathrm{NH}_{3}$ gas, the $\mathrm{KBH}_{4}$ begins to decompose around $580^{\circ} \mathrm{C}$ to produce $\mathrm{BH}_{3}$. When the heating temperature rises to $657^{\circ} \mathrm{C}$, which is the eutectic melting temperature of $\mathrm{NaCl}-\mathrm{KCl}$, the liquid phase environment generated by the molten salt envelopes and penetrates the raw material, preventing the transitional volatilization of $\mathrm{NH}_{4} \mathrm{Cl}$ and slowing down the reaction rate to reduce the loss of generated $\mathrm{NH}_{3}$ and $\mathrm{BH}_{3}$ with nitrogen. $\mathrm{NH}_{3}$ and $\mathrm{BH}_{3}$ are further reacted to form gaseous $\mathrm{B}_{3} \mathrm{~N}_{3} \mathrm{H}_{6}$ intermediates, and this is followed by the slow dehydrogenation of $\mathrm{B}_{3} \mathrm{~N}_{3} \mathrm{H}_{6}$ to produce $\mathrm{BN}$ nanoparticles. Finally, the $\mathrm{BN}$ nanoparticles aggregate into nuclei and grow into flake-like structures along the $\mathrm{BN}$ nuclei. The products were washed several times with distilled water to obtain the final product of BN nanoflakes.

Antioxidant analysis of r-BN. Studying the antioxidant properties of substances is usually by means of a differential thermal analyzer or the establishment of oxidation kinetics models. In this work, to understand the 


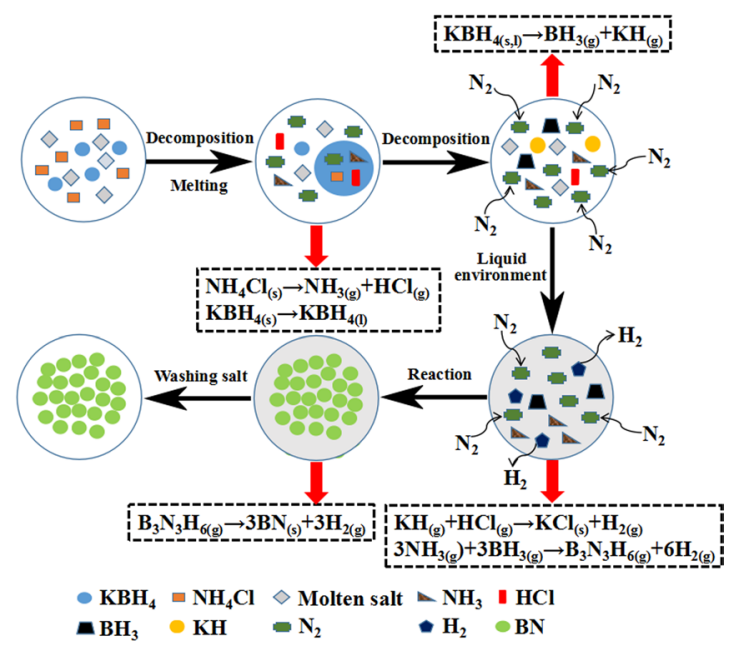

Figure 11. Schematic diagram of the $\mathrm{r}-\mathrm{BN}$ synthesis by molten salt method.
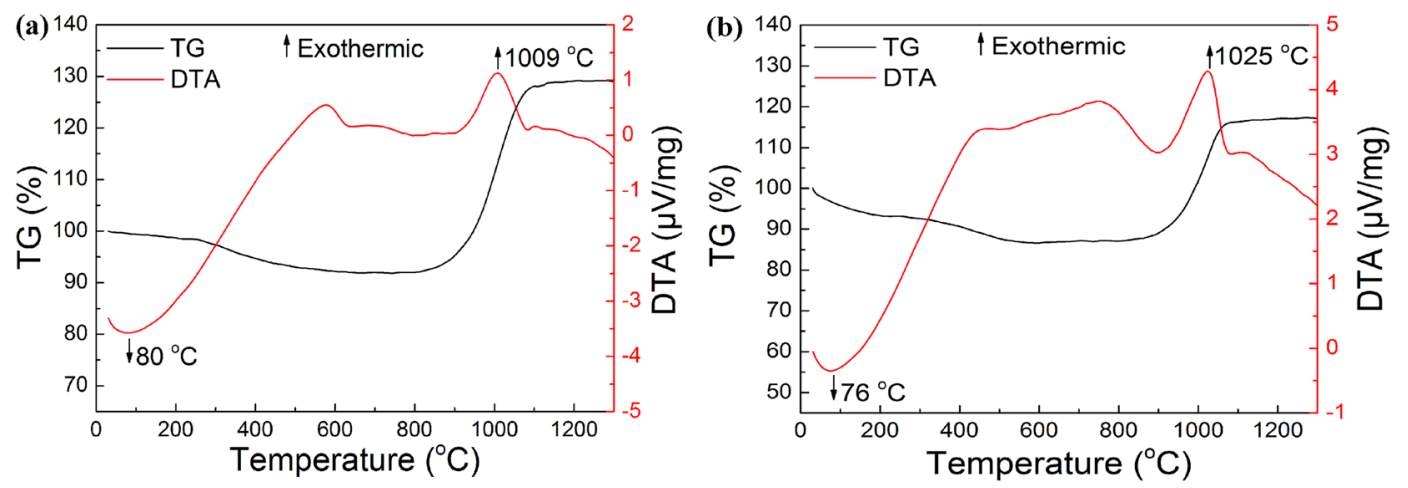

Figure 12. TG-DTA curves of the as-prepared BN nanoflakes in air: (a) With salt; (b) Without salt.

oxidation resistance of the synthesized BN nanoflakes, the as-prepared BN was subjected to TG and DTA tests. Figure 12 shows the TG-DTA curves of the as-prepared r-BN nanoflakes in air. The TG-DTA curves of the r-BN synthesized at $1100^{\circ} \mathrm{C}$ in $\mathrm{NaCl}-\mathrm{KCl}$ eutectic salts are shown in Fig. 12a. There is an endothermic peak at $80^{\circ} \mathrm{C}$, and the mass loss was due to the volatilization of water molecules in the sample. In addition, a pronounced exothermic peak appears at $1009^{\circ} \mathrm{C}$, which starts at $894^{\circ} \mathrm{C}$ and ends at $1084^{\circ} \mathrm{C}$, and the mass of the sample increases and begins to oxidize at $894^{\circ} \mathrm{C}$. Compared with the r-BN triangular nanoplates prepared by Bao et al. (BN started to oxidize at $\left.800^{\circ} \mathrm{C}\right)^{28}$, the oxidation resistance increased by approximately $100^{\circ} \mathrm{C}$. This result indicates that the as-prepared $\mathrm{BN}$ has excellent oxidation resistance and has good application prospects for high-temperature environments. In addition, when the heating temperature is $800-1200^{\circ} \mathrm{C}$, the $\mathrm{BN}$ is oxidized to $\mathrm{B}_{2} \mathrm{O}_{3}$ with an increase of approximately $37 \%$ in mass. Theoretically, $\mathrm{BN}$ is oxidized to $\mathrm{B}_{2} \mathrm{O}_{3}$ with an increase of approximately $40 \%$ in mass, indicating that part of the synthesized BN was not oxidized.

Figure $12 \mathrm{~b}$ shows the TG-DTA curves of the $\mathrm{r}-\mathrm{BN}$ synthesized at $1100^{\circ} \mathrm{C}$ without adding salt. When the temperature is lower than $600^{\circ} \mathrm{C}$, the sample quality decreases as the heating temperature increased. Furthermore, an exothermic peak appears at $1025^{\circ} \mathrm{C}$, which starts at $901^{\circ} \mathrm{C}$ and ends at $1085^{\circ} \mathrm{C}$. When the heating temperature is $800-1200^{\circ} \mathrm{C}$, the $\mathrm{BN}$ is oxidized to $\mathrm{B}_{2} \mathrm{O}_{3}$ with an increase of approximately $30 \%$ in mass. Compared with the synthesis of $\mathrm{BN}$ by MSS, this indirectly shows that the BN particles synthesized without the addition of salt were larger. Moreover, this can be confirmed by Figs $3 \mathrm{~d}$ and $4 \mathrm{~d}$.

\section{Conclusions}

This study shows that the use of the MSS made it easier to synthesize high-purity r-BN nanoflakes with good morphology in a nitrogen atmosphere at low temperatures. $\mathrm{KBH}_{4}$ and $\mathrm{NH}_{4} \mathrm{Cl}$ were used as the main raw materials. The effect of salt addition and non-addition on the formation of $\mathrm{r}$-BN was compared, and the heating temperature was also an important factor in the synthesis. High-purity $\mathrm{r}$ - BN was synthesized at $650{ }^{\circ} \mathrm{C}$ by using the MSS. However, with no salt added, r-BN was synthesized at $900^{\circ} \mathrm{C}$. As the heating temperature increased to $1000^{\circ} \mathrm{C}$, compared with the $\mathrm{r}-\mathrm{BN}$ synthesized without salt, the $\mathrm{r}-\mathrm{BN}$ synthesized using the molten $\mathrm{NaCl}-\mathrm{KCl}$ salt had a uniform morphology. The grain diameter was $200-300 \mathrm{~nm}$ and the thickness was $40-70 \mathrm{~nm}$. In addition, at $900-1100^{\circ} \mathrm{C}$, the specific surface area of BN synthesized by the MSS at $1000^{\circ} \mathrm{C}$ was the largest, at $294.26 \mathrm{~m}^{2} / \mathrm{g}$. Furthermore, the $\mathrm{BN}$ prepared at $1100^{\circ} \mathrm{C}$ had good oxidation resistance in air, and its elastic modulus value was approximately $1.60 \mathrm{GPa}$. 


\section{Data availability}

For original data, please contact dingjun@wust.edu.cn.

Received: 28 June 2019; Accepted: 23 October 2019;

Published online: 08 November 2019

\section{References}

1. Yin, J., Li, X. M., Zhou, J. X. \& Guo, W. L. Ultralight three-dimensional boron nitride foam with ultralow permittivity and superelasticity. Nano Lett. 13, 3232-3236 (2013).

2. Zou, C. R. et al. Ablation behavior and mechanism of $\mathrm{SiO}_{2 \mathrm{f}} / \mathrm{SiO}_{2}, \mathrm{SiO}_{2 \mathrm{f}} / \mathrm{BN}$ and $\mathrm{Si}_{3} \mathrm{~N}_{4 \mathrm{f}} / \mathrm{BN}$ radar wave transparent composites. Corros. Sci. 139, 243-254 (2018).

3. Zhao, Y. J., Zhang, Y. J., Gong, H. Y., Sun, H. B. \& Li, Q. S. Gas pressure sintering of $\mathrm{BN} / \mathrm{Si}_{3} \mathrm{~N}_{4}$, wave-transparent material with $\mathrm{Y}_{2} \mathrm{O}_{3}$ $\mathrm{MgO}$ nanopowders addition. Ceram. Int. 40, 13537-13541 (2014).

4. Zhi, C. Y. et al. Towards thermoconductive, electrically insulating polymeric composites with boron nitride nanotubes as fillers. $A d v$. Funct. Mater. 19, 1857-1862 (2009).

5. Li, Q. et al. Preparation of flake hexagonal BN and its application in electrochemical detection of ascorbic acid, dopamine and uric acid. Sensor. Actuat. B-Chem. 260, 346-356 (2018).

6. Ashton, T. S. \& Moore, A. L. Foam-like hierarchical hexagonal boron nitride as a non-traditional thermal conductivity enhancer for polymer-based composite materials. Int. J. Heat Mass Tran. 115, 273-281 (2017).

7. Mandelli, D., Leven, I., Hod, O. \& Urbakh, M. Sliding friction of graphene/hexagonal-boron nitride heterojunctions: a route to robust superlubricity. Sci. Rep. 7, 10851 (2017).

8. Katuku, K., Koursaris, A. \& Sigalas, I. High-temperature stability of polycrystalline cubic boron nitride cutting tool materials in air. Corros. Sci. 64, 55-63 (2012).

9. Choudhuri, I. \& Pathak, B. Ferromagnetism and half-metallicity in a high-band-gap hexagonal boron nitride system. Chemphyschem 19, 153-161 (2018).

10. Kamalakar, M. V., Dankert, A., Bergsten, J., Ive, T. \& Dash, S. P. Enhanced tunnel spin injection into graphene using chemical vapor deposited hexagonal boron nitride. Sci. Rep. 4, 6146 (2014).

11. Zheng, M. T., Liu, Y. L., Wang, P. \& Xiao, Y. Synthesis and formation mechanism of cubic boron nitride nanorods in lithium bromide molten salt. Mater. Lett. 91, 206-208 (2013).

12. Melaibari, A., Molian, P. \& Shrotriya, P. Laser/waterjet heat treatment of polycrystalline cubic/wurtzite boron nitride composite for reaching hardness of polycrystalline diamond. Mater. Lett. 89, 123-125 (2012).

13. Ye, L. F. et al. Catalyzed synthesis of rhombohedral boron nitride in sodium chloride molten salt. Ceram. Int. 42, 11626-11633 (2016).

14. Zhong, B., Zhang, X. D., Xia, L., Yu, Y. L. \& Wen, G. W. Large-scale fabrication and utilization of novel hexagonal/turbostratic composite boron nitride nanosheets. Mater. Design 120, 266-272 (2017).

15. Shen, L., Tan, B. J., Willis, W. S. \& Suib, S. L. Characterization of dip-coated boron nitride on silicon carbide fibers. J. Am. Ceram. Soc. 77, 1011-1016 (1994).

16. Gautam, C. et al. Synthesis and porous h-BN 3D architectures for effective humidity and gas sensors. RSC Adv. 6, 87888-87896 (2016).

17. Liang, J. L. et al. In-situ conversion of porous boron nitride to highly crystallized nanoplates-assembled hexagonal boron nitride nanoarchitectures via a metal ion-assisted annealing method. J. Alloy. Compd. 705, 749-755 (2017).

18. Lin, L. X., Zheng, Y., Zheng, Y. \& Wei, K. M. Facile synthesis of hexagonal boron nitride fibers and flowers. Mater. Lett. 61, 1735-1737 (2007).

19. Torabi, O., Golabgir, M. H., Tajizadegan, H. \& Jamshidi, A. Mechanochemical behavior of magnesium-boron oxide-melamine ternary system in the synthesis of h-BN nanopowder. Ceram. Int. 42, 6450-6456 (2016).

20. Ye, L. F. et al. Facile synthesis of hexagonal boron nitride nanoplates via molten-salt-mediated magnesiothermic reduction. Ceram. Int. 41, 14941-14948 (2015).

21. Tian, Y. et al. Ultrahard nanotwinned cubic boron nitride. Nature 493, 385-388 (2013).

22. Solozhenko, V. L., Kurakevych, O. O. \& Godec, Y. L. Creation of nanostuctures by extreme conditions: high-pressure synthesis of ultrahard nanocrystalline cubic boron nitride. Adv. Mater. 24, 1540-1544 (2012).

23. Huang, Y. J., Chen, H. W., Peng, X. S., Zhang, B. T. \& Chen, B. Shock waves preparing cubic boron nitride nanoparticles. J. Alloy. Compd. 741, 875-877 (2018).

24. Chubarov, M., Pedersen, H., Högberg, H. \& Henry, A. On the effect of silicon in CVD of sp² hybridized boron nitride thin films. Cryst. Eng. Comm. 15, 455-458 (2013).

25. Chubarov, M. et al. Boron nitride: A new photonic material. Physica B 439, 29-34 (2014).

26. Chubarov, M., Pedersen, H., Högberg, H., Czigany, Z. \& Henry, A. Chemical vapour deposition of epitaxial rhombohedral BN thin films on SiC substrates. Cryst. Eng. Comm. 16, 5430-5436 (2014).

27. Oku, T., Hiraga, K., Matsuda, T., Hirai, T. \& Hirabayashi, M. Twin structures of rhombohedral and cubic boron nitride prepared by chemical vapor deposition method. Diamond Relat. Mater. 12, 1138-1145 (2003).

28. Bao, K. Y. et al. Synthesis of highly crystalline rhombohedral BN triangular nanoplates via a convenient solid state reaction. J. Solid State Chem. 182, 925-931 (2009).

29. Ding, J., Deng, C. J., Yuan, W. J., Zhu, H. X. \& Zhang, X. J. Novel synthesis and characterization of silicon carbide nanowires on graphite flakes. Ceram. Int. 40, 4001-4007 (2014).

30. Ding, J., Zhu, H. X., Li, G. Q., Deng, C. J. \& Li, J. Growth of SiC nanowires on wooden template surface using molten salt media. Appl. Surf. Sci. 320, 620-626 (2014).

31. Ding, J., Guo, D., Deng, C. J., Zhu, H. X. \& Yu, C. Low-temperature synthesis of nanocrystalline ZrC coatings on flake graphite by molten salts. Appl. Surf. Sci. 407, 315-321 (2017).

32. Chen, Y., Deng, C. J., Yu, C., Ding, J. \& Zhu, H. X. Molten-salt nitridation synthesis of cubic ZrN nanopowders at low temperature via magnesium thermal reduction. Ceram. Int. 44, 8710-8715 (2018).

33. Liu, Z. L. et al. Molten salt synthesis and characterization of $\mathrm{SiC}$ whiskers containing coating on graphite for application in $\mathrm{Al}_{2} \mathrm{O}_{3}$ SiC-C castables. J. Alloy. Compd. 777, 26-33 (2019).

34. Yang, T. et al. Molten salt synthesis of mullite nanowhiskers using different silica sources. Int. J. Min. Met. Mater. 22, 884-891 (2015).

35. Sun, C. H., Guo, C. L., Ma, X. J., Xu, L. Q. \& Qian, Y. T. A facile route to prepare boron nitride hollow particles at $450^{\circ} \mathrm{C}$. J. Cryst. Growth 311, 3682-3686 (2009).

36. Qu, J. L., Li, Q., Luo, C., Cheng, J. \& Hou, X. M. Characterization of flake boron nitride prepared from the low temperature combustion synthesized precursor and its application for dye adsorption. Coatings 8, 214 (2018).

37. Wang, M. et al. High yield synthesis of novel boron nitride submicro-boxes and their photocatalytic application under visible light irradiation. Catal. Sci. Technol. 1, 1159-1165 (2011). 
38. Zhou, D. S. et al. Influence of hexagonal boron nitride on the selective catalytic reduction of $\mathrm{NO}$ with $\mathrm{NH}_{3}$ over $\mathrm{CuOX} / \mathrm{TiO}{ }_{2}$. RSC Adv. 5, 31708-31715 (2015).

39. Liu, Z. Y. et al. Novel multifunctional cheese-like 3D carbon-BN as a highly efficient adsorbent for water purification. Sci. Rep. 8, 1104 (2018).

40. Kumar, E. M., Sinthika, S. \& Thapa, R. First principles guide to tune h-BN nanostructures as superior light-element-based hydrogen storage materials: role of the bond exchange spillover mechanism. J. Mater. Chem. A 3, 304-313 (2014).

41. Li, Q. et al. Porous hexagonal boron nitride whiskers fabricated at low temperature for effective removal of organic pollutants from water. Ceram. Int. 42, 8754-8762 (2016).

42. Ding, J., Deng, C. J., Yuan, W. J., Zhu, H. X. \& Li, J. The synthesis of titanium nitride whiskers on the surface of graphite by molten salt media. Ceram. Int. 39, 2995-3000 (2013).

43. Ding, J. et al. Preparation and characterisation of porous biomorphic SiC/C ceramic from molten salt. Ceram. Int. 41, 11539-11545 (2015).

44. Ding, J., Zhu, H. X., Li, G. Q., Deng, C. J. \& Chai, Z. N. Catalyst-assisted synthesis of $\alpha-\mathrm{Si}_{3} \mathrm{~N}_{4}$ in molten salt. Ceram. Int. 42, 2892-2898 (2016).

45. Chai, Z. N. et al. Ni-catalyzed synthesis of hexagonal plate-like alpha silicon nitride from nitridation of Si powder in molten salt media. Adv. Powder Technol. 27, 1637-1644 (2016)

46. Kan, X. Q. et al. Low-temperature fabrication of porous $\mathrm{ZrC/C}$ composite material from molten salts. Ceram. Int. 43, 6377-6384 (2017).

47. Kan, X. Q., Ding, J., Zhu, H. X., Deng, C. J. \& Yu, C. Low temperature synthesis of nanoscale titanium nitride via molten-saltmediated magnesiothermic reduction. Powder Technol. 315, 81-86 (2017).

48. Liu, H. X. et al. Low-temperature synthesis and properties of VN nanopowder via a combined molten salt nitridation and magnesium thermal reduction. Ceram. Int. 45, 16638-16644 (2019).

49. Wang, X. et al. Preparation and application of $\mathrm{ZrC}$-coated flake graphite for $\mathrm{Al}_{2} \mathrm{O}_{3}-\mathrm{C}$ refractories. J. Alloy. Compd. 788, 739-747 (2019).

50. Hu, J. Q. et al. Synthesis and characterization of nanocrystalline boron nitride. J. Solid State Chem. 148, 325-328 (1999).

51. Bi, J. Q. et al. Large-scale synthesis of BN nanotubes using carbon nanotubes as template. Mater. Lett. 63, 1299-1302 (2009).

\section{Acknowledgements}

The authors acknowledge the support of colleagues at the College of Materials and Metallurgy at Wuhan University of Science and Technology. The authors would also like to acknowledge the financial support from the

National Natural Science Foundation of China (grant nos 51502215, 51574187 and 51602232), and the Natural Science Foundation of Hubei Province (grant no. 2018CFA022).

\section{Author contributions}

Yang Chen, Jun Ding and Chengji Deng designed the experiments. Yang Chen, Xing Wang, Chao Yu, Jun Ding, Chengji Deng and Hongxi Zhu performed the measurements. Yang Chen, Xing Wang and Chengji Deng analyzed the experimental data. Yang Chen and Jun Ding wrote the manuscript. All the authors discussed the results and commented the manuscript.

\section{Competing interests}

The authors declare no competing interests.

\section{Additional information}

Correspondence and requests for materials should be addressed to J.D.

Reprints and permissions information is available at www.nature.com/reprints.

Publisher's note Springer Nature remains neutral with regard to jurisdictional claims in published maps and institutional affiliations.

(c) (i) Open Access This article is licensed under a Creative Commons Attribution 4.0 International License, which permits use, sharing, adaptation, distribution and reproduction in any medium or format, as long as you give appropriate credit to the original author(s) and the source, provide a link to the Creative Commons license, and indicate if changes were made. The images or other third party material in this article are included in the article's Creative Commons license, unless indicated otherwise in a credit line to the material. If material is not included in the article's Creative Commons license and your intended use is not permitted by statutory regulation or exceeds the permitted use, you will need to obtain permission directly from the copyright holder. To view a copy of this license, visit http://creativecommons.org/licenses/by/4.0/.

(c) The Author(s) 2019 